\title{
Effects of stimulus change in prepunishment alley segments on self-punitive behavior
}

\author{
STEPHEN T. PERCONTE, BETSEY A. BENSON, and DAVID L. BUTLER \\ Virginia Polytechnic Institute and State University, Blacksburg, Virginia 24061
}

\begin{abstract}
Three experiments investigated the effects of stimulus change during extinction on selfpunitive behavior. In Experiment 1, changing alley brightness cues in all three segments of the alley prior to extinction eliminated self-punitive behavior. That is, subjects given shock in the third alley segment during extinction did not differ from nonshocked subjects in alley speed or in the number of trials to extinction. In Experiment 2, with shock also administered in the third alley segment, self-punitive behavior was eliminated when the stimulus change was made in segment 1 or in segments 1 and 2 but was obtained when the change occurred in segment 2 or in the lower startbox. In Experiment 3, shock was administered in the second alley segment. Self-punitive behavior was not obtained when the lower startbox cues were changed but was obtained with stimulus change in the upper startbox or in segment 1 . The results are consistent with an expanded version of the Mowrer-Brown conditioned-fear hypothesis.
\end{abstract}

Vicious-circle (VC), or self-punitive, behavior refers to punishment-induced response facilitation. In the standard paradigm (e.g., Brown, Martin, \& Morrow, 1964), an animal is given shock-escape training in a runway followed by one of two extinction procedures. In the regular-extinction (RE) procedure, all shock is removed from the runway; in the punished-extinction (PE) condition, shock is maintained in one alley segment but is discontinued in the startbox and in the rest of the alley. The PE subjects respond on a reliably greater number of trials and run faster than do the RE subjects. Thus, PE subjects continue to respond despite the fact that if they remained in the start area they would receive no shock (Brown, 1969).

The most widely accepted explanation of VC behavior is the Mowrer-Brown conditioned-fear hypothesis (Brown, 1969). This hypothesis proposes that when PE subjects encounter shock in the alley during extinction the shock is paired with cues present in the alley, thereby providing additional fearconditioning trials. Fear conditioned to the shockzone cues generalizes to the startbox and continues to motivate running on subsequent trials. The running response continues to be reinforced by fear and pain reduction upon entry into the safe goalbox. In contrast, RE subjects encounter no shock in the alley; fear is no longer reinforced, and locomotor responding extinguishes rapidly.

These data were presented at the annual meeting of the Midwestern Psychological Association, Chicago, 1979. Experiments 1 and 2 were completed by the first author in partial fulfillment of the requirements for the MS degree at Virginia Polytechnic Institute and State University. Requests for reprints should be sent to Betsey A. Benson, Psychology Department, VPI\&SU, Blacksburg, Virginia 24061 .
Because VC behavior is assumed to be dependent on the continued conditioning of fear during punished extinction, it follows that if the stimuli in the shock zone were altered for the extinction trials, VC behavior should be reduced. The reasoning is that the cues paired with shock during extinction would be less similar to the unchanged cues in the start area and the rest of the alley. Thus, the generalization of fear to the startbox and, hence, the motivation for running, would be reduced. However, Brown (1970, Experiment 1) found no reduction in $\mathrm{VC}$ behavior when, prior to extinction, he added black and white vertical stripes to the formerly gray walls of the shock area. A possible reason for this result is based on the established finding that the pairing of a CS and UCS is most effective when there is some interval between the onsets of these stimuli (Mackintosh, 1974, p. 61ff). On this basis, the unchanged stimuli which immediately preceded shock in the Brown study would continue to be optimally paired with shock during punished extinction regardless of the change in the cues of the shock region (Eaton, 1975). It follows that stimulus changes in prepunishment regions of the alley are more likely to affect $\mathrm{VC}$ behavior than are changes in the shock zone. Furthermore, VC behavior should be differentially affected by the particular location of the stimulus change in the prepunishment area. The present studies tested these implications by changing brightness cues prior to extinction in various sections of the runway.

\section{EXPERIMENT 1}

The first experiment tested the hypothesis that stimulus change can affect self-punitive responding. Subjects received training trials in an all-black or all- 
white runway and startbox. For half of the subjects, alley brightness cues were changed from black to white or from white to black in the three alley segments prior to extinction. The remaining subjects received extinction trials in which alley brightness cues, black or white, remained the same as in training. Half of the subjects in each of the above conditions received $R E$, and half $P E$, extinction trials. It was expected that $\mathrm{PE}$ subjects in the no-change condition would be more resistant to extinction than their RE controls, whereas PE subjects in the stimulus-change condition would be more similar to their RE controls.

\section{Method}

Apparatus. The apparatus was similar to that described by Brown, Martin, and Morrow (1964). Briefly, it consisted of a twotiered startbox, a $183 \mathrm{~cm}$ three-segment alley, and a goalbox. The upper tier of the startbox, the alley, and the goalbox had hinged Plexiglas lids. The walls of the startbox and the alley segments were white, but could be altered by the placement or removal of black cardboard inserts. The goalbox was black with white, vertical, 3.8-cm-wide stripes on the walls which joined similar white stripes on the goalbox floor.

The upper tier of the startbox $(23.3 \times 11.3 \times 17.3 \mathrm{~cm})$ had a trapdoor which could be released to drop the subject onto the grid floor of the lower startbox compartment $(40.3 \times 25.1 \times$ $20.0 \mathrm{~cm}$ ). This compartment led directly into the first of three grid-floored alley segments $(61.0 \times 11.6 \times 20.3 \mathrm{~cm})$. The goalbox measured $44.9 \times 25.1 \times 20.0 \mathrm{~cm}$ and had a solid wooden floor. A manually operated guillotine door was employed to confine subjects in the goalbox.

Individual photocells were located $2.2 \mathrm{~cm}$ from the goalbox end of the lower startbox and of each alley segment. Each runway photocell was connected to one of four Lafayette electric timers via two Hunter photocell relays. Latencies were recorded to the nearest 100th sec. All clocks were activated by the release of the startbox trapdoor and were stopped by the interruption of their corresponding photobeam. Starting time, time per segment, and total time were obtained for each trial. However, only total time in the form of total speed will be reported because this measure was representative of the findings obtained with the other measures. Total time was defined as the interval between the release of the trapdoor and the interruption of the photobeam at the end of the third alley segment, $2.2 \mathrm{~cm}$ from the entrance to the goalbox.

A Grason-Stadler shock generator (Model 700) delivered a constant current ac shock of $.8 \mathrm{~mA}$ to the grids of the lower startbox and of each alley segment. The grids were $3 \mathrm{~cm}$ in diameter, spaced $1.2 \mathrm{~cm}$ apart (center to center).

Subjects and Design. The subjects were 40 Long-Evans derived male hooded rats bred in the departmental colony. They were 90-110 days old on Day 3 of the experiment. The subjects were housed in pairs and given food and water ad lib.

The rats were randomly assigned to groups in a 2 by 2 by 2 repeated-measures design $(n=5)$ with extinction condition (presence or absence of shock in the third alley segment, PE or RE), alley brightness ( $\mathrm{W}$ or $\mathrm{B}$ ), and the presence (C) or absence of stimulus change during extinction as the between-subjects factors and blocks of trials as the within-subjects factor. Animals in the RE group received extinction trials with no stimulus change and with no shock present in the startbox or alley. The PE group had extinction trials with no stimulus change but with shock in the third alley segment at the same level used in training. Groups CPE and CRE were given the PE or RE extinction trials with stimulus change in all three alley segments. If a subject in one of these groups was trained in a black runway and startbox, extinction trials took place with the three alley segments changed to white, or vice versa. Brightness cues in both levels of the startbox and in the goalbox remained the same as in training. Direction of stimulus change was balanced by training half the animals in each group in a block runway and half in a white runway. The appropriate stimulus change was made during the intertrial interval (ITI) between the last training trial and the first extinction trial.

Procedure. Two subjects were run per day, one RE and one PE rat, selected randomly from one of the stimulus-change conditions and from one of the alley brightness conditions ( $W$ or $B$ ).

On Day 1, each rat received $10 \mathrm{~min}$ of handling. On Day 2, each rat received $5 \mathrm{~min}$ of handling followed by $5 \mathrm{~min}$ of exploration of the runway. The latter procedure consisted of placing the rat into the upper level of the startbox, releasing the trapdoor, and dropping the rat into the lower startbox compartment. The rat had access to the entire alley and no shock was present.

Training began on Day 3. Each subject received a total of 15 trials. Trials $1-6$ were pretraining trials to shape the running response. On Trial 1, the startbox and the goalbox were connected in tandem and shock was administered in the lower compartment of the startbox. For Trials 2 and 3 , the first electrified $61-\mathrm{cm}$ alley segment was inserted between the startbox and the goalbox. The second electrified alley segment was added for Trials 4 and 5 , and the third, for Trial 6 . Nine additional training trials (Trials 7-15) were given in which all three alley segments were included.

For each training trial, the subject was dropped from the upper level of the startbox onto the grid floor of the lower compartment. The guillotine door was lowered upon the animal's entry into the goalbox. Goalbox confinement was $30 \mathrm{sec}$, after which the subject was transferred to an unpainted wooden holding cage $(35.2 \times$ $13.2 \times 20.2 \mathrm{~cm}$ ) for approximately $20 \mathrm{sec}$. Following this period the rat was placed in the upper startbox to begin the next trial. Total ITI was approximately $1 \mathrm{~min}$, timed from the subject's entry into the goalbox to the release of the startbox trapdoor for the next trial.

Extinction trials began immediately following the ITI of the last training trial and were administered for a total of 60 trials or until the subject failed to enter the goalbox within $60 \mathrm{sec}$. If a 60 -sec trial occurred in fewer than 60 trials, all remaining trials were assigned a total time of $60 \mathrm{sec}$.

\section{Results and Discussion}

For each subject, the median total time for each block of three trials was converted to a speed score $(\mathrm{cm} / \mathrm{sec})$. Mean total speed and the mean number of extinction trials completed were the dependent variables. Pretraining trials (Trials 1-6) were not included in the analyses.

Training. Figure 1 presents group means of total speed for the three blocks of training trials. Analysis of variance indicated significant effects only for Blocks $[\mathrm{F}(2,64)=23.93, \mathrm{p}<.0001]$, Stimulus Change by Blocks $[F(2,64)=3.28, p<.04]$, and Stimulus Change by Alley Brightness $[F(1,32)=5.42, p<.03]$.

Simple effects analyses of the Stimulus Change by Blocks interaction indicated that Blocks was significant in both stimulus-change conditions (ps $<.0003$ ). In both the change and no-change conditions, speed reliably increased from Block 1 to Block 2, whereas Blocks 2 and 3 did not differ reliably. Comparisons of the stimulus-change conditions for each block separately showed that Stimulus Change was not reliable on any block ( $\mathrm{ps}>.06$ ). Analyses comparing stimulus-change conditions within each alley-brightness condition revealed that Stimulus Change was not reliable in either condition ( $p s>.09$ ). In addition 


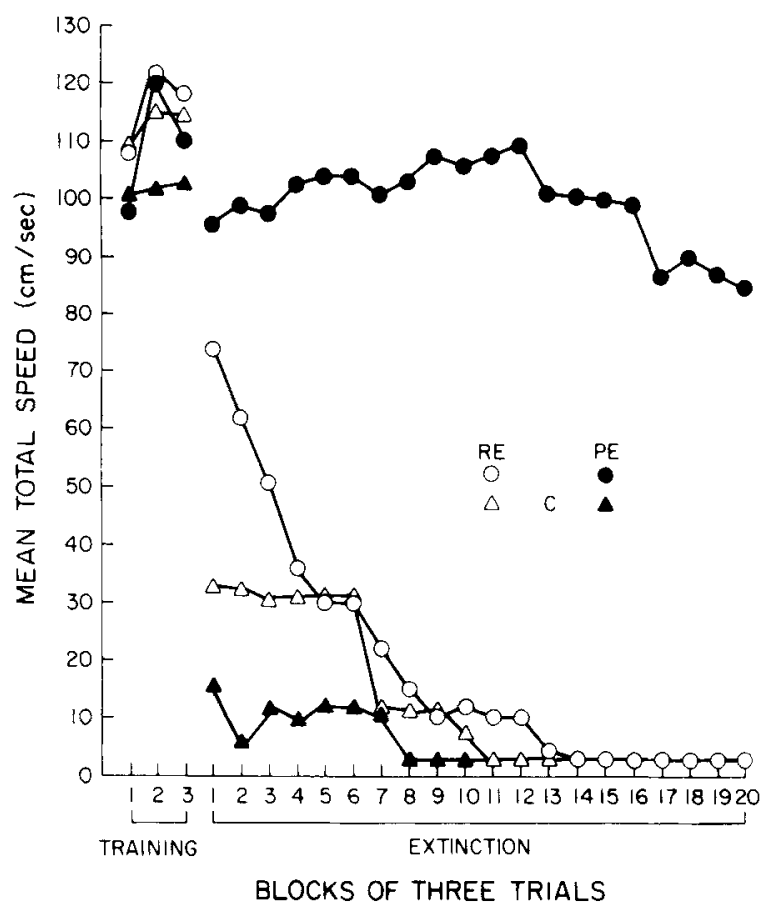

Figure 1. Mean total speed in blocks of three trials for regularextinction (RE) and punished-extinction (PE) groups, with (C) or without stimulus change during extinction.

there was no reliable effect of Alley Brightness within either stimulus-change condition ( $\mathrm{ps}>.08$ ). Thus, these analyses did not identify reliable sources of the interactions. Because stimulus change was a dummy variable in these analyses, it seems reasonable to attribute the observed interactions to random error. As such, the interpretation of the extinction data should not be affected.

Extinction. Figure 1 also presents group means of total speed across blocks of extinction trials. The PE group responded consistently more rapidly than the other three extinction groups. Analysis of variance indicated significant effects of Stimulus Change $[\mathrm{F}(1,32)=24.38, \mathrm{p}<.0001]$, Extinction Condition $[\mathrm{F}(1,32)=13.20, \mathrm{p}<.001]$, Blocks $[\mathrm{F}(19,608)=9.06$, $\mathrm{p}<.0001]$, Stimulus Change by Extinction Condition $[F(1,32)=18.74, p<.0001]$, and Extinction Condition by Blocks $[F(19,608)=5.04, p<.0001]$. The effect of Alley Brightness was not significant, and it did not interact with any of the other factors.

Simple effects analyses indicated that Blocks was reliable in the $R E$ condition $(p<.0001)$ but not in the PE condition ( $p>.30)$. The CPE and CRE groups did not differ $(p>.20)$, whereas the PE group ran reliably faster than the RE group $(p<.004)$. The PE group also ran reliably faster than the CPE group $(p<.0001)$, and the two RE groups did not differ reliably.

Table 1 (Experiment 1) presents the mean number of trials to extinction for the four groups (alley brightness collapsed). An analysis of variance indicated significant effects for Stimulus Change $[F(1,32)=$ $21.43, \mathrm{p}<.0001]$, Extinction Condition $[\mathrm{F}(1,32)=$ $9.42, p<.004$ ], and for Stimulus Change by Extinction Condition $[F(1,32)=17.53, p<.0002]$. Neither the main effect of Alley Brightness nor any interactions involving this factor were significant.

Simple effects analyses revealed that the PE group was more resistant to extinction than the RE group $(\mathrm{p}<.001)$. The CPE and CRE groups did not differ, nor was there a reliable difference between the RE and CRE conditions. The PE group completed reliably more extinction trials than the CPE group ( $p<$ .0001 ).

These data demonstrate that stimulus change in the three alley segments prior to extinction eliminated VC behavior; the CPE and CRE groups did not differ in alley speed or in the number of extinction trials completed. However, typical punishment-induced response facilitation was obtained in the $\mathrm{PE}$ group that did not encounter a stimulus change.

\section{EXPERIMENT 2}

Experiment 2 tested the hypothesis that stimulus change in some prepunishment areas would affect $\mathrm{VC}$ behavior more than would stimulus change in other prepunishment locations. Changes in brightness cues were made prior to the extinction phase in either the lower portion of the startbox (LS), in segment $1(\mathrm{~S} 1)$, in segments 1 and $2(\mathrm{~S} 1+2)$, or in segment 2 (S2).

\section{Method}

Apparatus. The apparatus was the same as that used in Experiment 1 . Brightness cues were changed by adding or removing black cardboard inserts in the appropriate section of the apparatus during the ITI between the last training trial and the first extinction trial. The goalbox was black with white stripes for all trials.

Subjects and Design. The subjects were 80 Long-Evans derived male hooded rats bred in the departmental colony. The animals were the same age and were housed and maintained in the same manner as those in Experiment 1. The subjects were assigned ran-

Table 1

Mean Number of Trials to Extinction and Standard Deviations for Each Group in Each Experiment

\begin{tabular}{lrrrrr}
\hline Group & Mean & SD & Group & Mean & SD \\
\hline \multicolumn{5}{c}{ Experiment 1 } \\
PE & 44.8 & 23.9 & RE & 14.0 & 13.7 \\
CPE & 3.0 & 6.7 & CRE & 8.3 & 10.4 \\
& \multicolumn{5}{c}{ Experiment 2 } \\
LSPE & 26.8 & 25.1 & LSRE & 11.1 & 9.9 \\
S1PE & 13.3 & 22.7 & S1RE & 7.8 & 9.7 \\
S1+2PE & 5.6 & 7.7 & S1+2RE & 8.8 & 9.3 \\
S2PE & 33.5 & 28.7 & S2RE & 5.0 & 4.4 \\
& \multicolumn{7}{c}{ Experiment 3 } \\
USPE & 53.8 & 17.7 & USRE & 27.9 & 18.1 \\
LSPE & 15.3 & 18.4 & LSRE & 12.4 & 14.8 \\
S1PE & 54.0 & 18.9 & S1RE & 23.5 & 28.8 \\
\hline
\end{tabular}


domly to groups in a 2 by 2 by 4 repeated-measures design $(n=5)$ with extinction condition (RE or PE), alley brightness (W or B), and location of stimulus change (LS, S1, S1 $+2, \mathrm{~S} 2$ ) as the between-subjects variables and blocks of trials as the within-subjects variable. Brightness cue changes from white to black and from black to white were controlled as in Experiment 1.

Procedure. Four subjects were run in each session: two subjects from PE groups and two from RE groups, selected randomly. Handling and exploration, pretraining trials (Trials 1-6), and training trials (Trials 7-15) were conducted in the same way as in Experiment 1. Half of the rats in each group received training trials in an all-white alley and startbox, and half received them in an all-black alley and startbox.

During the extinction phase, PE subjects were shocked in the third alley segment and RE subjects were not shocked. The stimulus change (white to black, or vice versa) during extinction occurred in the first and second alley segments for Groups $S 1+2 R E$ and $S 1+2 P E$, in only the first segment for Groups SIRE and S1PE, in only the second segment for Groups S2RE and S2PE, and in only the lower portion of the startbox for Groups LSRE and LSPE. Extinction trials continued for 60 trials or until the rat failed to enter the goalbox within $60 \mathrm{sec}$ on a single trial.

\section{Results and Discussion}

Training. Figure 2 presents group means of total speed for the three blocks of training trials. There was a reliable increase in speed across blocks $[F(2,128)$ $=11.31, \mathrm{p}<.00011$. No other main effects or interactions were significant.

Extinction. Figure 2 also presents group means of total speed across blocks of extinction trials. The figure indicates that the S2PE and LSPE groups ran faster than the other two PE groups, and that total speed of the S2PE group was more stable than

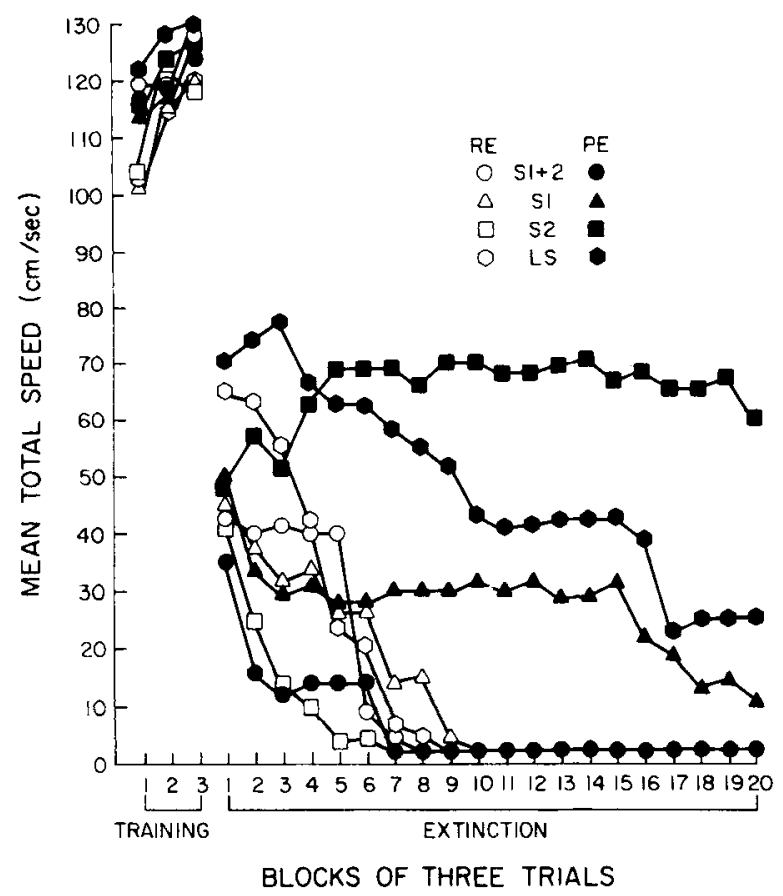

Figure 2. Mean total speed in blocks of three trials for regularextinction (RE) and punished-extinction (PE) groups, with stimulus change during extinction in the lower startbox (LS), segment 1 (S1), segments 1 and 2 (S1 +2$)$, or segment 2 (S2). that of the LSPE group. The RE groups appear to be similar in total speed.

Analysis of variance revealed significant effects for Extinction Condition $[F(1,64)=10.05, p<.002]$, Blocks $[F(19,1216)=18.54, p<.0001]$, and the interactions between Location of Stimulus Change and Blocks $[F(57,1216)=2.44, p<.0001]$, Extinction Condition and Blocks $[F(19,1216)=4.65, \mathrm{p}<.0001]$, and Location of Stimulus Change and Extinction Condition $[F(3,64)=3.24, p<.03]$. The main effect of Location of Stimulus Change was marginally reliable $[F(3,64)=2.31, p<.08]$. Neither the main effect of Alley Brightness nor any interaction involving this factor was significant.

Simple effects analyses indicated that Blocks was significant for all locations except $\mathrm{S} 2$ (ps $<.0001$ ) and that the Extinction Condition by Blocks interaction was reliable only in $\mathrm{S} 2(\mathrm{p}<.0001)$. Only the S2PE group did not decrease in speed across trials. Extinction condition was reliable only in the LS and $\mathrm{S} 2$ conditions ( $\mathrm{ps}<.03$ ). Location of change had a significant effect in the PE groups $(p<.04)$ but not in the RE groups. The S2PE group ran reliably faster than both the S1PE and S1 + 2PE groups, and the LSPE group differed reliably from the $\mathrm{S} 1+2 \mathrm{PE}$ group ( $\mathrm{p}<.05$, Duncan multiple range test).

Table 1 (Experiment 2) presents the mean number of extinction trials completed by each group. An analysis of variance of these data revealed reliable effects of Location of Stimulus Change $[F(3,64)=2.97$, $\mathrm{p}<.04]$, Extinction Condition $[\mathrm{F}(1,64)=9.26, \mathrm{p}<$ .003 ], and the Location of Change by Extinction Condition interaction $[F(3,64)=3.63, p<.02]$. Simple effects analyses indicated that the PE group completed significantly more extinction trials than the corresponding RE group only in the $S 2$ condition $(p<.01)$. In the LS condition, the effect of Extinction Condition was marginally reliable $(p<.06)$. The effect of Location of Stimulus Change was reliable only for the PE groups $(p<.05)$. A Duncan multiple range test indicated that the S2PE group completed significantly more extinction trials than the $\mathrm{S} 1 \mathrm{PE}$ and the $\mathrm{S} 1+2 \mathrm{PE}$ groups ( $\mathrm{ps}<.05$ ), which did not differ. The LSPE group completed more extinction trials than the $S 1+2 \mathrm{PE}$ group and did not differ from the S2PE and S1PE groups.

These results confirmed the hypothesis that stimulus change in different prepunishment locations has different effects on VC behavior. The S1 $+2 \mathrm{PE}$ and S1PE groups did not differ from their RE controls in alley speeds or in the number of trials to extinction, whereas the S2PE group showed reliable VC behavior and the LSPE groups showed some evidence of VC behavior.

\section{EXPERIMENT 3}

Experiment 3 was an extension of Experiments 1 and 2. It employed the typical VC paradigm in which 
PE subjects are shocked in the second alley segment during the extinction phase. Stimulus changes were made in three prepunishment regions of the apparatus, the upper startbox (US), the lower startbox (LS), and segment 1 (S1).

\section{Method}

Apparatus. The apparatus was the same as that used in Experiments 1 and 2. Brightness cues were changed by adding black cardboard inserts in the appropriate section of the apparatus during the ITI between the last training trial and the first extinction trial. The goalbox was black with white stripes for all trials.

Subjects and Design. The subjects were 60 Long-Evans derived male hooded rats bred in the departmental colony. The animals were the same age and were housed and maintained in the same manner as the subjects in Experiments 1 and 2. The subjects were assigned randomly to one of six extinction conditions in a 2 by 3 repeated-measures design $(n=10)$ with the presence or absence of shock during extinction (RE or PE) and the location of stimulus change (US, LS, S1) as the between-subjects variables and blocks of trials as a within-subject variable. Stimulus changes were made only from white to black in this experiment because no reliable effect of the direction of change was found in Experiments 1 and 2.

Procedure. Four subjects, two PE and two RE, selected randomly, were run in each session. Handling and exploration, pretraining, and training trials were conducted in the same manner as in Experiments 1 and 2 except that all subjects were trained in a white alley and startbox. During the extinction phase, PE subjects encountered shock in the second alley segment and RE subjects received no shock. The stimulus change (white to black) prior to extinction occurred in the upper startbox for Groups USRE and USPE, in the lower startbox for Groups LSRE and LSPE, and in the first segment for Groups SIRE and SIPE. Extinction trials continued for 60 trials or until one 60 -sec trial occurred.

\section{Results and Discussion}

Training. Figure 3 presents group means of total speed for the three blocks of training trials. An analysis of variance revealed that running speed increased across blocks of trials $[F(2,108)=3.70, p<.03]$ and that the RE groups ran faster than the PE groups during training $[\mathrm{F}(1,54)=5.87, \mathrm{p}<.02]$. This unanticipated difference in speed between the RE and $P E$ groups was not expected to interfere with the interpretation of the extinction data because the observed difference was in the direction opposite to that expected during the extinction phase.

Extinction. Figure 3 also presents group means of total speed across blocks of extinction trials. The figure indicates that the USPE and S1PE groups ran faster than the LSPE group and all of the RE groups. Analysis of variance indicated significant effects for Location of Stimulus Change $[F(2,54)=12.75, p<$ $.0001]$, Extinction Condition $[F(1,54)=34.22$, $p<$ $.0001)$, and Blocks $[\mathrm{F}(19,1026)=18.42, \mathrm{p}<.0001]$. Reliable interactions were obtained for Location of Change by Blocks $[\mathrm{F}(38,1026)=2.68, \mathrm{p}<.0001]$, Extinction Condition by Blocks $[F(19,1026)=7.32$, $p<.0001$, Location of Change by Extinction Condition $[\mathrm{F}(2,54)=4.93, \mathrm{p}<.01]$, and Location of Change by Extinction Condition by Blocks $[\mathrm{F}(38,1026)$ $=4.14, \mathrm{p}<.0001]$.

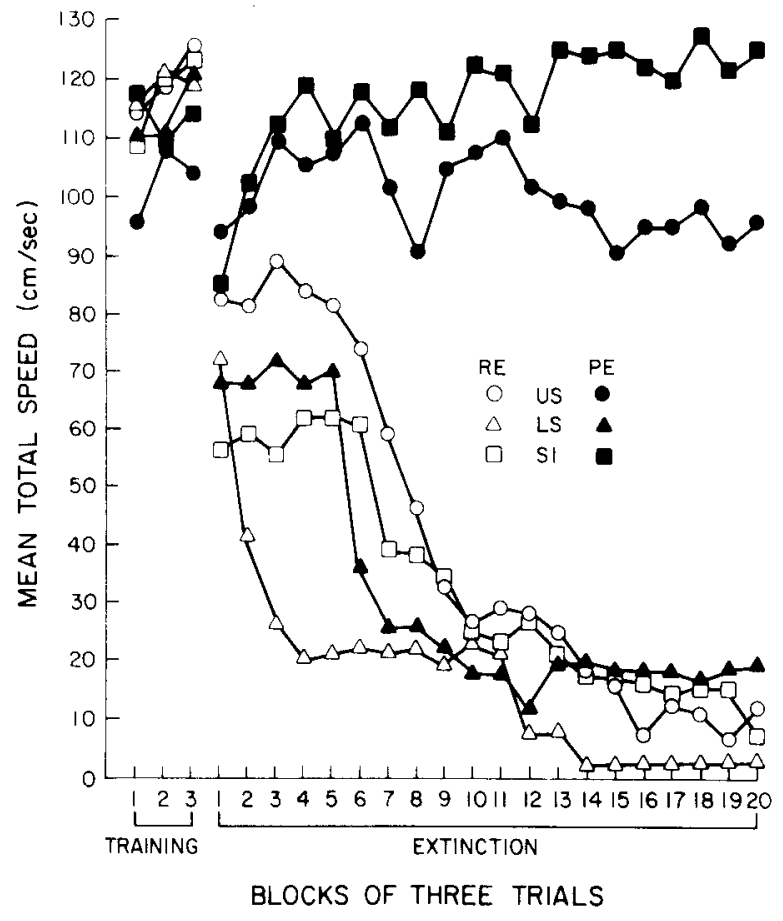

Figure 3. Mean total speed in blocks of three trials for regularextinction (RE) and punished-extinction (PE) groups with stimulus change during extinction in the upper startbox (US), the lower startbox (LS), or segment 1 (S1).

Simple effects analyses indicated that the Extinction Condition by Blocks interaction was reliable at all three locations of stimulus change (ps $<.005$ ) and that Extinction Condition was reliable only in the US and $\mathrm{S} 1$ conditions ( $\mathrm{ps}<.001$ ). Further analyses over trial blocks revealed that all RE groups and the LSPE group decreased in speed (ps $<.001$ ), whereas the USPE group did not change $(p>.05)$ and the S1PE group reliably increased in speed $(p<.0001)$. The location of stimulus change had a reliable effect in the PE groups $(p<.0002)$ but not in the RE groups $(p>.10)$. The USPE and S1PE groups did not differ, and both ran reliably faster than the LSPE group (ps $<.05$, Duncan multiple range test).

Table 1 (Experiment 3) presents the mean number of trials to extinction for the six groups. Analysis of variance indicated reliable effects of Extinction Condition $[F(1,54)=17.97, p<.001]$, Location of Stimulus Change $[F(2,54)=13.84, p<.001]$, and the Extinction Condition by Location of Stimulus Change interaction $[F(2,54)=3.35, p<.05]$. Simple effects analyses indicated that the RE and PE groups in the US and S1 conditions differed reliably (ps $<.005$ ), whereas the LSRE and LSPE groups did not differ $(p>.05)$. The S1PE and USPE groups did not differ significantly, and both groups completed significantly more extinction trials than the LSPE group (ps $<.05$ ), whereas no differences among the RE groups were reliable (ps $>.05$, Duncan multiple range test). 
These results indicate that stimulus change in different prepunishment locations has different effects on VC behavior when shock is in the second alley segment during extinction. The LSPE group did not differ from its RE control group, whereas the USPE and SIPE groups showed reliable evidence of selfpunitive behavior.

\section{GENERAL DISCUSSION}

These experiments demonstrated that changing alley stimuli just prior to extinction can affect selfpunitive behavior. In Experiment 1, stimulus change in all three alley segments eliminated $\mathrm{VC}$ behavior, whereas typical self-punitive responding was obtained with PE subjects that did not encounter stimulus change. Experiments 2 and 3 demonstrated that stimulus change in prepunishment areas of the runway had varying effects on VC behavior, depending on its location and on the location of shock. These differential effects on extinction performance occurred in the PE groups and not in the RE groups. This result suggests that the change in stimuli influenced the manner in which the continued conditioning of fear, which occurs during punished extinction but not during regular extinction, affects performance.

An account of these data which is entirely consistent with the basic tenets of the Mowrer-Brown (Brown, 1969; Melvin, 1971) conditioned-fear hypothesis can be offered. This account is based on the assumption that the stimuli in the alley segment just preceding shock acquire maximum fear-eliciting properties, that a typical stimulus generalization gradient of fear extends from this segment to the startbox (Melvin, 1971), and that during training subjects learn a running response to the external stimuli, including shock, as well as to the stimuli produced by fear. Furthermore, during extinction, fear motivates the locomotor response and entry into the goalbox reinforces the response by pain and/or fear reduction. Additionally, it is assumed that a punishing effect can degrade performance when locomotion occurs from one segment of the runway to a more feareliciting segment if the differential in fear is sufficiently large.

VC behavior was obtained when the stimulus change was made in the alley segment immediately preceding the shock area (Group S2PE in Experiment 2 and Group S1PE in Experiment 3). Although the changed cues would result in a stimulus generalization decrement of fear, the optimal location of the segment with respect to shock would result in rapid conditioning of fear to the new cues. Thus, a sizable amount of fear would soon be present to maintain the running response. On the first trial or two, the fear present in the earlier segments of the runway should motivate the running response already learned in training and should carry the subject into the shock segment. In this regard, it is important to recall that the subject had learned during training to run forward in the presence of shock, and this learning would operate when the subject stepped onto the electrified grid. Support for this analysis is provided by the increases in speed of running shown by these two groups over the initial blocks of extinction trials. If fear had not rapidly become conditioned to the changed cues, one would not expect this increased strength of self-punitive behavior or its maintenance.

When the stimulus change occurred two alley segments before the shock (Group S1PE in Experiment 2 and Group LSPE in Experiment 3), VC behavior was not obtained. In these instances, fear would be minimal in these segments at the beginning of extinction because of the stimulus change. Locomoting from the segment with the changed stimuli to the next segment, which in each case just preceded shock, would result in a marked increase in fear because of the optimal location of the latter segment for the conditioning of fear. This large increase in fear would punish locomotion enough so that the response would not be maintained and VC behavior would be prevented.

Some evidence for VC behavior occurred in Experiment 2 when the stimulus change occurred in the lower startbox (Group LSPE), a location three segments removed from the shock. In this case, presumably there was a sufficient amount of fear elicited (e.g., from the grid floor and from the cues associated with being dropped onto the grid) to motivate locomotor behavior previously learned to these cues. The subject, when running from the lower startbox to segment 1 , would encounter only a modest increase in fear because of the distance of segment 1 from the shock segment. Such a gradual increase in fear based on a stimulus generalization gradient from the area near shock to earlier sections of the runway occurs in the standard paradigm and does not prevent VC behavior. Thus, self-punitive behavior can be maintained when the stimuli in the lower startbox are changed if the shock occurs in the third alley segment, but, as explained above, it can be eliminated if the shock occurs in the second alley segment (Experiment 3) because the location of shock determines how much fear is present in the first alley segment.

The effect of changing the stimuli in the upper startbox apparently had no effect on VC behavior. Group USPE of Experiment 3 performed like a normal punished-extinction group, such as the PE group of Experiment 1 .

Changing the stimuli in both segments 1 and 2 (Group S1 + 2PE of Experiment 2) prevented selfpunitive behavior. In this case, fear would very quickly become conditioned to the second segment because of its nearness to the shock presented in segment 3 . 
Inasmuch as the changed stimuli in segment 1 were identical to those of segment 2, a large amount of fear would also be elicited in segment 1 . However, only a small amount of fear would be elicited in the lower startbox because of its distance from the shock source during training and because of the dissimilarity of its cues from those being conditioned during extinction. Therefore, a large increase in fear would occur when locomoting from the lower startbox to segment 1 . The resultant punishment of the locomotor response would prevent VC behavior.

This type of analysis can be applied to the results obtained by Brown (1970, Experiment 2) and Brown, Beier, and Lewis (1971). In these studies, in which shock was located in the second segment during extinction, a solid insert was placed over the grids in the lower startbox and first segment of the runway just prior to extinction. VC behavior was obtained even with the stimulus change. In this case, fear would be quickly conditioned to the changed floor cues of the segment preceding shock, and because of stimulus similarity, a large amount of fear would also be elicited in the startbox. Thus, fear would be present to motivate the running response, and self-punitive responding would ensue. From this analysis, it might seem to follow that VC behavior should have been found in Experiment 1, in which brightness throughout the alley was changed. However, in Experiment 1, the stimuli were not changed in the startbox and, hence, little fear conditioned during extinction would generalize to this area to provide motivation for the locomotor response.

The implication of these interpretations is that whether or not self-punitive behavior occurs depends upon a delicate balance between the amounts of fear present in the successive segments of the runway. Too large an increase in fear from one segment to the next can prevent $\mathrm{VC}$ behavior by punishing the running response. On the other hand, sufficient fear is needed to motivate the response.

It should be noted that although these interpretations are largely post hoc, they are consistent with known principles of learning, and they are open to empirical test. The amount of fear present in any segment at any point in training or extinction can be measured by determining its effect on the occurrence of some other index response.

\section{REFERENCES}

Brown, J. S. Factors affecting self-punitive locomotor behavior. In B. A. Campbell and R. M. Church (Eds.), Punishment and aversive behavior. New York: Appleton-Century-Crofts, 1969.

Brown, J. S. Self-punitive behavior with a distinctively marked punishment zone. Psychonomic Science, 1970, 21, 161-163.

Brown, J. S., Beier, E. M., \& Lewis, R. W. Punishment-zone distinctiveness and self-punitive locomotor behavior in the rat. Journal of Comparative and Physiological Psychology, 1971, 77, 513-520.

Brown, J. S., Martin, R. C., \& Morrow, M. S. Self-punitive behavior in the rat: Facilitative effects of punishment on resistance to extinction. Journal of Comparative and Physiological Psychology, 1964, 57, 127-133.

EAton, N. K. A detailed chronological review of the literature dealing with self-punitive locomotor behavior: 1947-1974. JSAS Catalog of Selected Documents in Psychology, 1975, 5, 323.

Mackintosh, N. J. The psychology of animal learning. London: Academic Press, 1974.

Melvin, K. B. Vicious circle behavior. In H. D. Kimmel (Ed.), Experimental psychopathology: Recent research and theory. New York: Academic Press, 1971.

(Received for publication March 31, 1980; revision accepted August 27, 1980.) 